\title{
I collect, therefore I am
}

\author{
Sumayya Baasir \\ Media and Cultural Studies, The Graduate School, Universitas Gadjah Mada, Yogyakarta, \\ Indonesia \\ e-mail: sumayyabasir@gmail.com
}

\begin{abstract}
Being a fan means separated yourself from casual consumers. To be recognized as a fan, someone needs to devote themselves and spend a significant amount of money and time. They also have to build their own identity by doing a specialized consumption, collecting merchandise is an example of it. This paper aims to explore the relation between collecting merchandise as a tool of identity building within fans of an idol group, especially AKB48, Nogizaka46, and Keyakizaka46. The groups, created by Akimoto Yasushi, using oshimen (oshiteru members, a member that you support) system to form a special relationship between the idol and fan. The oshimen system makes the specialized consumption behavior to be even more specialized. This paper also aims to explore reasons behind collecting merchandise, as fans willing to buy and adding more merchandise to their possession. Finally, this paper aims to explore the pleasure of the collecting merchandise activity. Whether they'll get enough pleasure or an endless journey to get ultimate pleasure. The analysis relies on an interview with three respondents (a male and two females), ranging from nineteen to twenty-nine-year-old. The finding suggests that fans admit collecting merchandise is an irrational activity. The merchandise serves the purpose as a tool to build and strengthen their identity as 'true' fans, separated themselves from 'casual' and non-fans.
\end{abstract}

\section{Keywords}

collecting merchandise, fan, identity, idol, possession

\section{Introduction}

"Throughout myj life as fans, I already collect 5000 photo sets of my favorite member. Why I did this? I could not explain it easily, thus I re-think about the life of mine along."

Citation: Baasir, S. (2018). I collect, therefore I The sentence came when I was reading 48G, one of threads in 4chan, a forum that took platform bulletin board and relied on the anonymity of its users (allowing users express their opinions freely). Stunned, I moved to open a box that contains my collection all this time. A calendar I have never displayed, some key chains, six CDs, and dozens of photo sets are in it I thought the same question, "Why would I buy these things?" I never used it, the CD was only opened once: only to put it on my iTunes; the accompanying DVDs never played because of regional format data's differences; key chains that I only used one of them, while others I have not even opened its signet. Some photo packs are only opened once in a lifetime, occasionally looked at, re-photographed, and then inserted back to its case. The only merchandise that I often use is just a tote bag, for size and utility reason which is large enough for shopping. 
The thought not only hit me but also my friends who became fans of 48 group and collect their trinkets. One of them even breaks up with his girlfriend because he prefers to buy photobook of his favorite member than dinner with her. The same question reappeared as we talked about it "Why should I buy this? I just want to see Ikuchan (Ikuta Erika, a member of Nogizaka46) nothing else".

Fan relationships and collecting activities (mostly merchandise) is a close relationship that is not easily explained. Being a fan itself means separating away from ordinary consumers. To be called a fan, a person needs commitment, both in terms of time and in terms of cost. This is what distinguishes fans from ordinary consumers. Beside of commitment, fans also build and maintain the identity inherent in it. This identity formed through special consumption behavior and patterns. When a person becomes a fan and enters the world of fandom, then that is when he performs specialized consumption (Stevens, 2010, p.199). This is certainly self-identify as a fan, as well as to distinguish self with non-fans and casual fans (who are not involved deeply in something).

This concept becomes interesting in the context of AKB48 idol group's fandom and other groups under the "48G" affiliation. The idol group puts more quantity than quality. In short, there are so many members with each own personality. Here also the concept of oshimen (oshiteru members) introduced. The existence of this oshimen concept makes the pattern of specialized consumption become more specialized. The fan will buy merchandises associated with their oshimen only. This consumption behavior is a unique one. It is unique because they do not merely buy all the items produced, and it is unique because they keenly pick over which item to be bought. It is also unique to see how through the stuff they are connecting and building their identity as fans.

Consumption behavior is also associated with identity formation, that the identity of a person is formed directly through the goods he consumes. (Giddens' concept, 1991, p. 14) “...'how shall I live'? Has to be answered in day-to-day decision about how to behave, what to wear -and many other
things- as well as interpreted within the temporal unfolding of self-identity"

Identity is not something that a person gets directly from birth. The identity of one's self is something that must be preserved and established throughout ages. One way to maintain one's identity is to consume continuously (ibid, p.52). In the beginning, consumption used as a means to build a person's identity. However, in the next stage, consumption is a means to maintain one's identity. As a project that lasts for the rest of life, undoubtedly human will continue to consume throughout his life.

The collecting activity is a unique consumption behavior (McIntosh \& Schmeichel, 2002, p. 86). In order to be a collector, one must collect several series of the same item. Without regard to functionality, these items are collected. It means as a collector, the functional value is the priority of the umpteenth, not the main motivation. Another characteristic of a collector's collection is to store his/her collection for long periods. Therefore, we can see the various kinds of collectors around us. From the stamps collector, toys, and many other things that will amaze us briefly. Surely, for them, it is not a question of "what is the benefit of this stuff", but rather on other aspects.

This collecting behavior reappears at the concept of extended self (Belk, 1988, p. 141). Our self, according to Belk, is the whole of what we have (possession). The things we have, which we get from our work, play an important role in building the self-concept we want. If we want to look and feel rich, then buy branded goods. When we have the goods, then we feel rich. Conversely, when it is lost then there is likely a missing body part. The concept of extended self and possession is closely related to the concept of strength and resources that we have. The things we have will be part of us when we have the power (e.g. money), to buy and call it ours. When we have money, we have the power to conquer the things we want. When the goods are 'conquered' (bought) then we feel it is becoming part of us.

The merchandises are not cheap, especially as limited-produced commodities. It's merely like basic economic, demand that is not equal to production will make the value of a good thing increases. The merchandise produced and sold on a limited basis certainly has an above average value. This factor adds to the integration factor of the collection with its collectors. A high price means adding to the collector's efforts. They have to work harder in order to buy their intended merchandise. When the money is collected, they must check the availability of the merchandise. The desired merchandise will be owned when money and goods are available. This effort makes each collection valuable and makes the collectors feel invested in every merchandise collection. Then it is seen as part of themselves, the item now becomes one of the extended self that is outside themselves.

This research tends to uncover the merchandise collection activity among fans of 48 idol group. This research tries to explore further the motivation of fans that continuously buy and adding their merchandise 
collection. What makes them compelled to collect these items will be the basic question underlying this research. Furthermore, this study tried to see the relationship between collecting activities with the identity constructions of fans. Finally, this study tends to explore the pleasure factor in collecting activities of fans. Will there be a time where they are satisfied yet enough with his/her collections? Is there a moment where they say 'enough is enough'? On the other hand, is it true that there will be no pleasure in this activity?

The respondents of this research consisted of three people: two women and one man. Two respondents were in their late twenties and the rest is 19 years old. This selection motivated by the need to find variations of their motivation in collecting merchandise. While the age classification intended to look for variations in consumption patterns.

\subsection{The Idol that You Can Meet}

Idol is not something new in Japan. The history of idols can be traced from 1963, referring to the movie Cherchez l'idole or Aidoru o Sagasu or "In Search of An Idol". The presence of Sannin Musume (Three Young Girls) group, which consists of Minami Saori, Koyanagi Rumiko, and Amachi Mari started the appearance of idols in the Japanese entertainment industry. The 80's is known as the 'golden age of idols', in which many idols have sprung up. Some names that are still relevant today are Matsuda Seiko, Nakamori Akina, Koizumi Kyoko, and Ishikawa Hitomi. The 90's decade started as idol boom era with the emergence of Morning Musume (abbreviated as MoMusu) and SMAP (male idol group under Johnny's and Associates management). In the 2000s, the trend began to fade with the graduation of MoMusu core members and the emergence of big solo acts such as Amuro Namie, Hamasaki Ayumi, or Utada Hikaru who was in the solo scene. Idol Boom, which began in the mid-1980s to the late 90s, finally faded.

The appearance of AKB48 does not necessarily lead to a new boom idol, as it takes up to five years for the group to occupy the Oricon charts. AKB48 begins with Akihabara 48 project from Akimoto Yasushi. In this project, Akimoto proposed a unique concept which has never existed in Japan, namely idol you can meet. This concept is manifested by holding a daily performance at the theater, located on the 8th floor of Don Quijote, Akihabara, Tokyo. In addition, fans can also meet with the idols on the handshake (HS) event, which is done several times a month.

Subsequently, AKB48 franchise began to grow. This development began in 2008 with the emergence of SKE48. The group based in Nagoya and has a theater in Sunshine Sakae, Nagoya. SKE has special characteristics in which its members considered to have above average dancing skills. In 2010, NMB48 debuted with its single Zetsumetsu Kurokami Shoujo. NMB48 originally from Osaka and based in the Yoshimoto agency building located in Namba, Osaka. NMB emphasized the comedic ability of its members. This closely related to the role of Yoshimoto Kyouraku, the agency that oversees NMB48. This agency is home to leading comedians in Japan.

The next year's interval HKT48 established. The group is based in Fukuoka and has a theater inside Hawk Towns Mall in Hakata area. Recently HKT48 renovated its theater to accommodate more visitors, which shows a significant market growth. HKT48 known as a group with the youngest member, such as Sashihara Rino, winner of the annual event Senbatsu Sousenkyo. While the new 48 franchises come from northern Japan, Niigata. In November 2015, NGT48 introduced to the public during the release of their debut track titled Max Toki 365 de. NGT48 daily performs at the Lovela Building's theater, Niigata.

The popularity of group 48 is not only applicable in Japan. The franchise spreading into several neighboring countries that considered as a potential market. In 2012, AKS (48's license owner company) introduced two overseas 48 sister groups: JKT48 and SNH48. JKT48 concentrates in FX mall, fourth floor, Senayan, Jakarta. While SNH48 based in Shanghai. The latest AKS expansion is the establishment of BNK48 (based in Bangkok, Thailand), TPE48 (based in Taipei, Taiwan), and MNL48 (based in Manila, Philippines).

Meanwhile, on August 21, 2011, an official rival of 48 groups, Nogizaka46, established. Nogizaka is Sony Music Entertainment Japan's (SMEJ) attempt to succeed in the idol industry along with its boom following the success of AKB and other 48 groups. Nogizaka might be considering as SMEJ's attempt to regained profitable chance as they had previously sold AKB registered license. SMEJ, through DefStar, is the label that housed AKB until 2009. This project terminated when the single and album sales were devastating. AKB moved to King Records, a subsidiary of Avex Trax, which is SMEJ's rivalry. AKB's success under Avex makes SMEJ seem to lose enormous potential profit. 
Nogizaka46 has a different concept with 48. The group does not have a theater. The members have a different image of 48G's girls. 48G's members have 'ordinary girl' characteristic (ordinary-daily physical appearance), while the Nogizaka46 members have classic idol physical characteristics. On the promotion of Japan Expo 2014, Nogizaka46 members introduced as 'the ultimate example of Japanese classic beauty'. This characteristic easily recognized even only at a glance. They have an above average level of beauty, porcelain-like skins, elegant yet graceful. In addition to the physical aspect, SMEJ also gives more attention to the Nogizaka's music quality. Although in general recognized as typical idol music, but there are some melodies and other musical elements that make the song passable for the public (non-fans).

\section{2nd Album 5.25 Release!!}

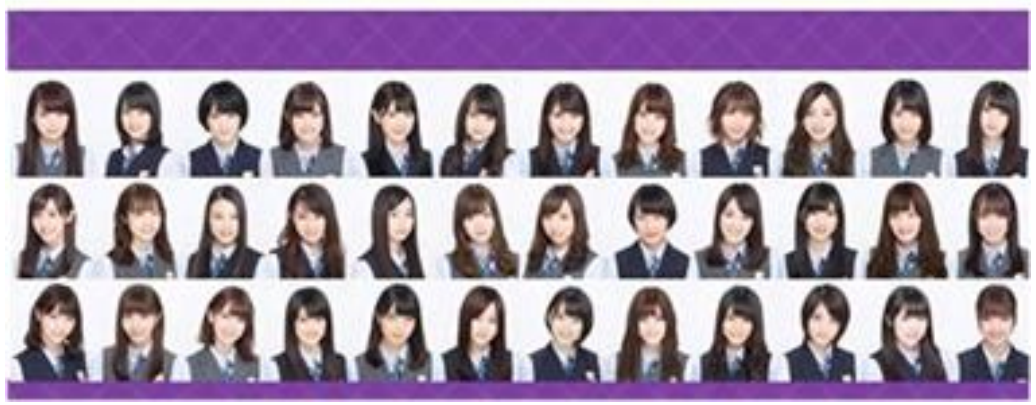

Fig. 1 List of Nogizaka46 member as for February 2016

The success achieved by Nogizaka (their latest single, Harujion Ga Sakukoro or The Time when Philadelphia Fleabane Blooms, sold at 700 thousand copies in a week) did not stop SMEJ. In May 2015, they introduced the sister group of Nogizaka46 named Toriizaka46. The group later changed its name to Keyakizaka46 shortly before its debut in March 2016. Keyakizaka46 debut single released on March 21, 2106, entitled Silent Majority. The single set a record as the highest-selling debut single in history after selling more than 270 thousand copies in a week. Even though both groups are under the same management, Keyakizaka is slightly different from Nogizaka. The group carries the theme of the military idol, which can be seen from their uniform style, dance movements, and its single debut.
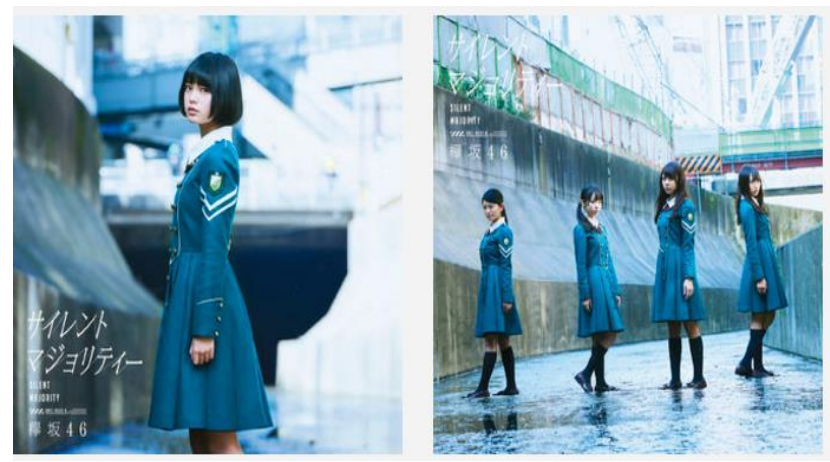

Fig. 2 Cover for Keyakizaka46's debut single, Silent Majority

\subsection{The Oshimen System}

When talking about fandom in the case of 48/46 groups, we need to learn about a special concept known as oshimen. The term is a play on word of oshiteru (support) and member, which means 'the member you support'. AKB fans (and others), call themselves 'supporters', not merely fans (Galbraith and Karlin 2012, p.21) In keeping with the idol concept in Japan, these fans see their idols 'flourish' in the entertainment world. From the clumsy young girl on stage to becoming a mature young woman, who is ready to 'graduate' and become the figure she aspires to (e.g. being a model, singer, or actress). 
The 48's franchise group, which has hundreds of members, has various member types that have their own character. Fans can choose what kind of members they likely to support. A fan can have one or more of the oshimen whom he/she supports.

The motivation to choose an oshimen ranged from physical attraction to the linkage of characters owned by each member. The closer the connection, the more support given.

Just like fans in general, 48/46 group fans also spend their time to dig up information about their preferred members. However, the intensity tends to be higher, because if you have an oshimen, you have to keep up with almost anything about the member. For example, by watching a theater show (or watching on-demand live streaming video), watching a television show attended by their oshimen, buying oshimen trinkets, and to some extent voting and meeting their oshimen directly in the sousenkyo or HS event, respectively. The fan-oshimen relationship is pictured below:

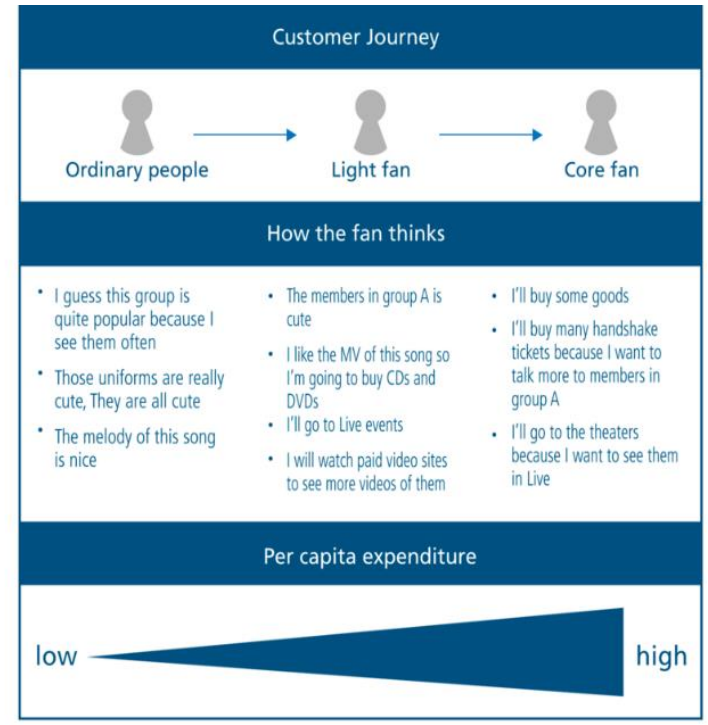

Fig. 3 Fan-Oshimen relationship

The concept of oshimen is not just a special relationship that exists between fans and idols. This concept will also have a lot of influence on consumption behavior undertaken by these fans. Fans will not collect merchandises that are not from his/her oshi. Here we can see the application of 'fandom as a specialized consumption' concept. More specifically, with the concept of oshimen, specialized consumption finds its realization.

As for the oshimen, the term oshihen exists. This term refers when a person changes his preferences from one member to another. This is fine, although others will underestimate fans that do oshihen. Fans that do oshihen usually labeled as 'traitor' or seen as the one with lesser loyalties, the behaviors that violate the norms of a scheme in which the relationship between fans and members becomes the core of the developed narrative.

\subsection{Support your Oshimen, Buy Their Products!}

As a business entity, 48/46 idol group does not put music as its main strength. Music is mere 'bonus' for fans along with building relationships with their oshimen. Undeniably indeed, business idol group made by Akimoto Yasushi is reviving the physical music industry from drowning. In the current era of digitalized music as it is today, it is hard to sell tens of thousands of CDs in a week. In contrary, the numbers of hundreds or thousands and even millions are easily achieved by the franchise. The youngest group in the franchise, Keyakizaka46, easily sold 270 thousand CDs in the first week after its release.

Although release the CDs regularly, 48/46 group also has a compelling line of business: merchandise selling. Gleaming result from this business is certain. In 2011, merchandise business contributed a profit of 60.5 million dollars. This value considered larger because AKB still has not reached its peak of popularity in that year. Merchandise produced by AKS (and Sony through group 46) sold for a limited time and amount basis. To buy this merchandise fans should go to the official stores of each group. In group 48, the store is 
mostly located in the theater area. As for 46 groups -Nogizaka for example, merchandise sold at Nogizaka Building located in Sony Music Entertainment building complex.

In addition to the official store, fans can visit the official page of each group to buy their merchandise. This page designed in such a way, allowing fans to immediately search for the latest trinkets oshimen. On the AKB page, for example, a link entitled as if "推しメンバ" exist. This link will be directed to a subsection containing the names of the members of this group, which divided by team, we just look for our oshimen name in that row, and we will see our oshimen merchandise available and produced in the month.

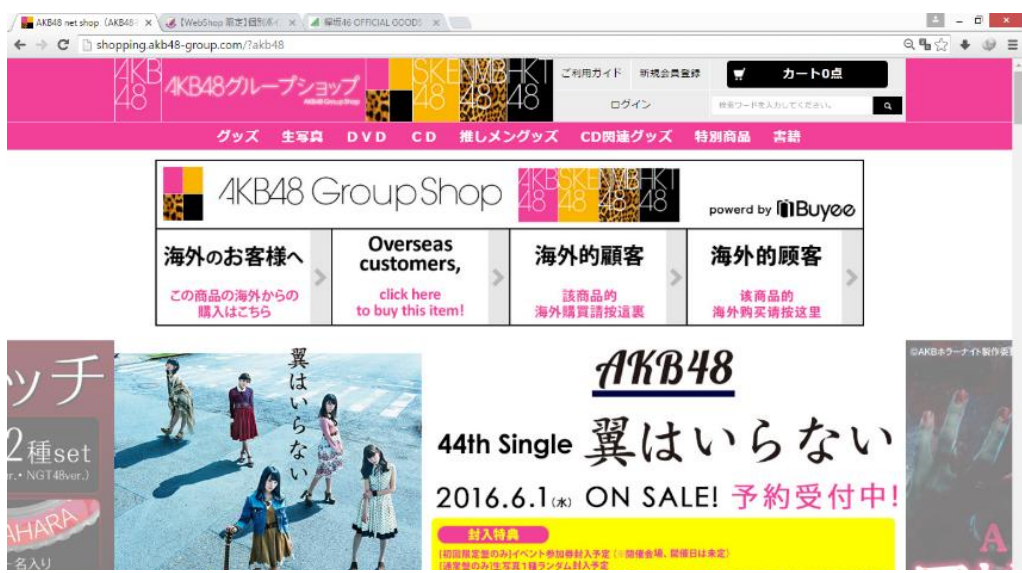

Fig. 4 AKB48 Official Online Shop

AKS and Sony provide a wide variety of merchandises. There are several types of merchandise available at all times, such as nama-sashin or photoset (with different designs monthly), uchiwa (a kind of towel that stretches during a concert), or a lightstick. There is also limited production when there are certain events, such as member's birthday t-shirts, concert memorabilia, or anniversary concert of the group. However, all types of merchandise are limited. It means that if the existing stock sold out, management will not produce it again. Fans who want the item has to look for his/her sought merchandise in other places such as Yahoo! Auction.

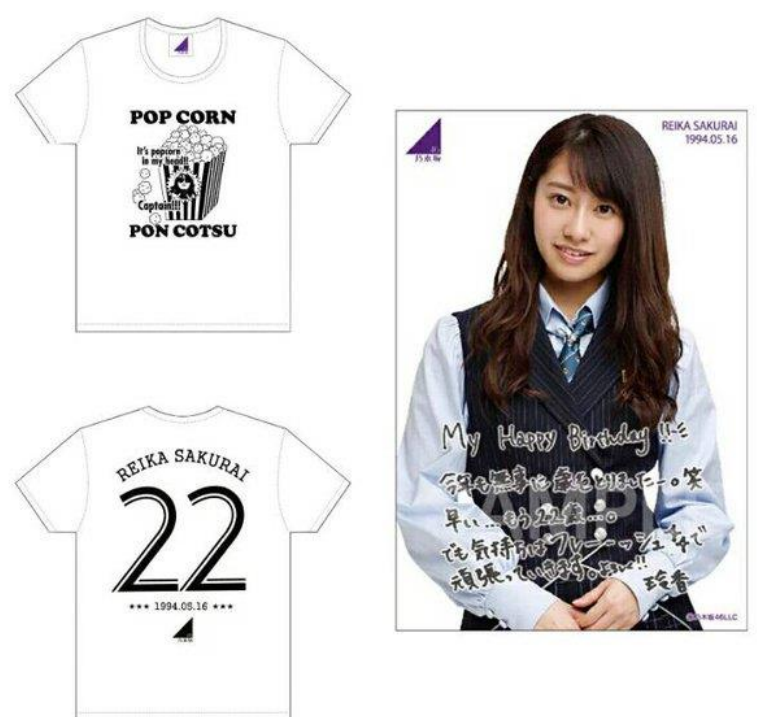

Fig. 5 Picture of Nogizaka46's Sakurai Reika's 22nd birthday shirt 


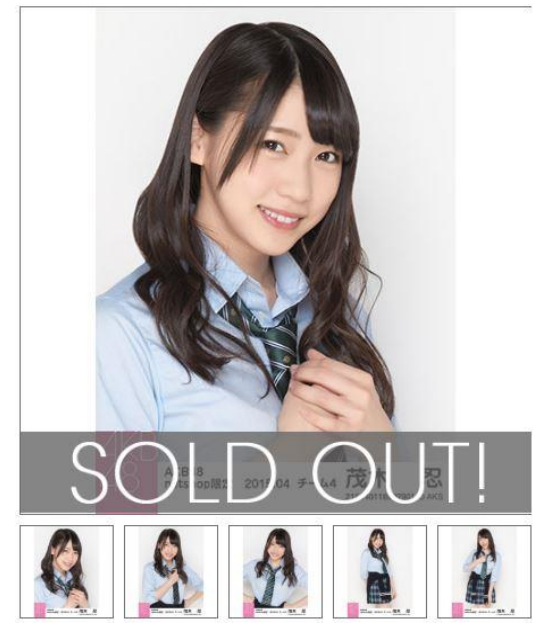

Fig. 6 AKB48's Mogi Shinobu's nama sashin (monthly photoset)

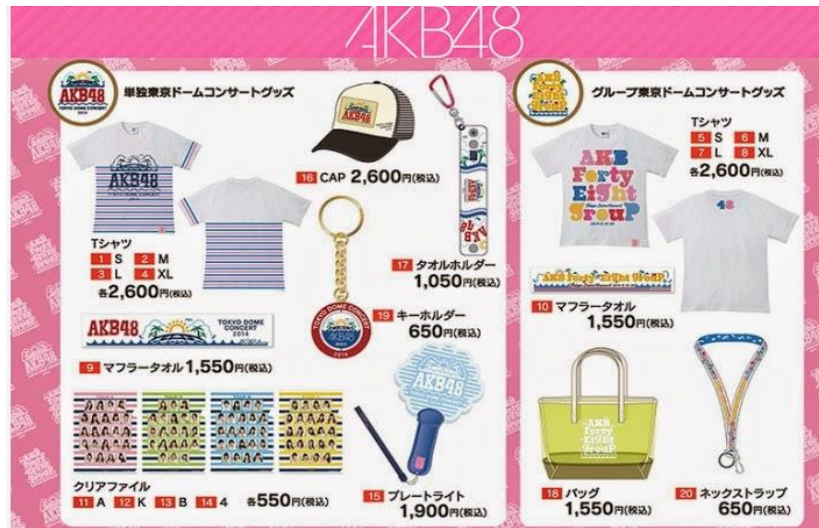

Fig. 7 AKB48's Concert memorabilia

\section{Results}

\subsection{Collect, Therefore I Am}

As mentioned earlier, this study tends to uncover the connection of collecting merchandise with the identity construction. Selection of respondents based on the motivation with a span of ten years. This difference will play a role in the consumption behavior of merchandise done by the respondents.

The first respondent is Sandi. He was my senior college but we just really did communicate when both knew we liked idol group 48 and had the same oshimen (at the time, Shinoda Mariko). Sandi is a 29-yearold who works as a scriptwriter in one of the production houses in Yogyakarta. In line with the income earned, Sandi is the respondent with the highest number of collections among others. Sandi regularly buys photoset, magazine, CD, uchiwa, or photobook. Variations of the collection are also very diverse, ranging from Sousenkyo posters to birthday t-shirts, which released during his oshimen's birthday.

In living as a fan, Sandi only focuses on two groups, AKB48 and Nogizaka46. These two groups followed as a group that attracted him into the idol world. As an illustration, Sandi is familiar with Japanese popular culture. He watches many dramas, collects action figures from famous anime, and has a side business in merchandise sales. Sandi has multiple oshimen from both groups. For AKB48 Sandi chose Shimazaki Haruka (Team A) as his Kami-oshi (absolute Oshimen), Mogi Shinobu (Team K), Omori Miyu (Team 4), Okada Nana (Team 4), and Okawa Rio (Team 4). While in Nogizaka46 Sandi chose Shiraishi Mai, Eto Misa, and Sagara Iori as his oshimen. Sandi also interested in Shida Manaka from Keyakizaka46. Except for Okawa, all his 
oshimen are over 18 years old. "I do not want to be seen as a lolicon (lolita complex)", he added. Lolicon, a behavior that likes someone much younger, is itself widely labeled as aberrant behavior; this narrative is reinforced by popular cultural products such as American Beauty movie, in which the main character (who prefer a much younger woman) stigmatised. Sandi's reasons for choose his oshimen are diverse so it makes him hard to explain it. "Is it ... for me it's not Oshi who finds us, but we were the one who finds Oshi".

Sandi's oshimen in AKB chosen because of their unusual characters. The first one, Paruru (Shimazaki Haruka's nicknames), famous for her salty attitude towards her fans. For Sandi, this character is interesting because it is 180 degrees different with the idol that he has known. Miyupon, Omori's nickname, attracts him for having a beautiful, adorable voice, not something imaginable when we look at her baby face. Okada Nana was chosen because, according to Sandi, looks cool on stage. Sandi himself had interacted with Okada when he attended AKB \& JKT concert which held on February 2015. While Mogi was picked to be his oshimen because of the extreme image gap she has. Although her physical appearance is beautiful, she is not ashamed to make a strange expression. Mogi is also often called as a hentai (pervert) character, who likes to grope others member's thighs. "I like Mogi less or more because you (writer, -red) talk about her constantly. I thought she's cool, but actually, she's a weirdo."

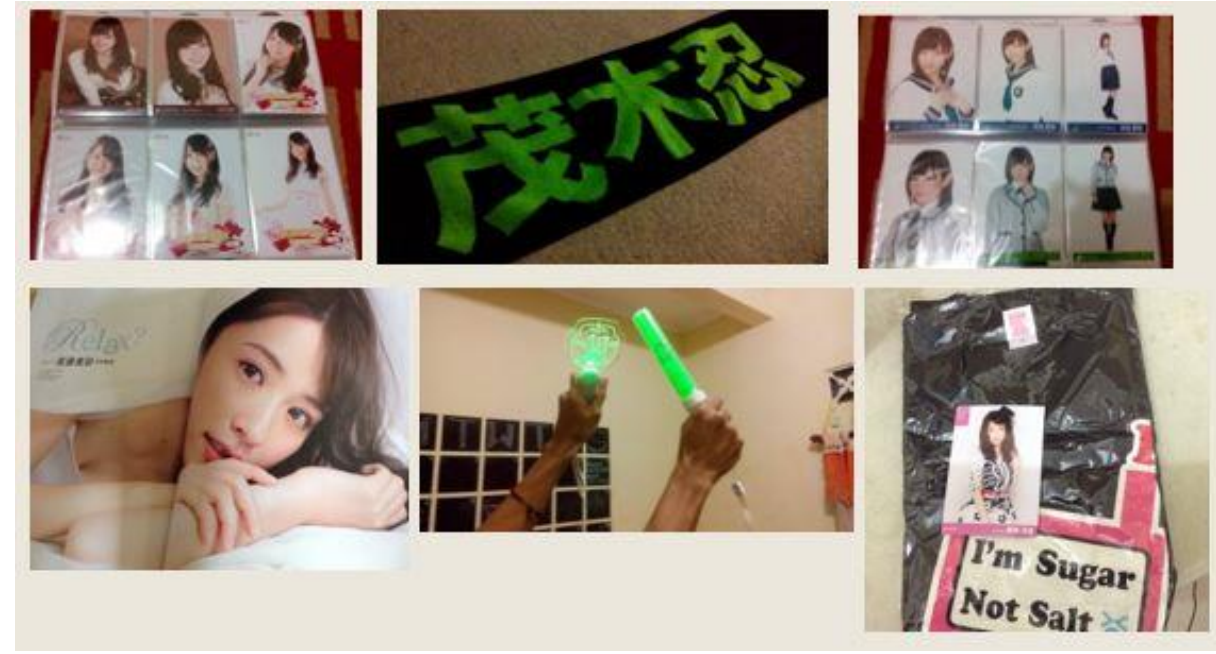

Fig. 8 Sandi's collection

For Nogizaka46, Sandi frankly admitted if his reason solely because of a physical matter. For example, Shiraishi and Eto. According to Sandi, Maiyan (Shiraishi's nickname) is the most beautiful woman he has ever seen. Sandi has its own view when describing her, "Maiyan's beauty is the same thing with the fact that earth is rounded, it's undeniable". The same reason he pointed out when describing Eto and Sagara.

"Besides Maiyan, to me, Misa is a beauty. Same with Maiyan, Misa is undeniably beautiful"

"When Nogi's second generation comes, I wasn't interested until I see Iori"

Sandi's collection is not far from the merchandise that contains his oshi's image. Sandi has a $22^{\text {nd }}$ birthday edition of Shimazaki and the $19^{\text {th }}$ for Mogi, T-shirts that he often wears at work. "Spreading wota virus in the office" becomes his reason. Sandi bought magazines that having Eto and Shiraishi for a few times. In addition, he has a photoset album for his oshimen pictures. For Sandi, collecting merchandise is proof of his existence as a fan. "How could we support our oshi? We are overseas fans, we cannot directly handshake or watch concerts. Merchandise collections are a form of our existence as fans. Outsiders know we are fans of this member because we have her merchandise". Holding through that viewpoint, Sandi does not mind spending 1.5 to 2 million rupiahs for this hobby. Sandi aware if this activity is not a rational one.

"Something that can not eliminate hunger and thirst; does not protect us from rain and heat, but we work hard to get it. This is a more emotionally based decision than the brain's ".

The same reason also expressed by Dev (a pseudonym), the second respondent in this research. Dev is a 28-year-old who works as an event organizer. Live in Bogor, yet familiar with the concept of the idol, 
because she is a fan of Morning Musume group. She is also familiar with Japanese popular culture, especially the Love Live anime. When 'K-Pop fever' boom, Dev joining SNSD's fandom (So Nyuh Shi Dae or Girls' Generation), KARA, and Wonder Girls. Dev is a newcomer in oshimen culture of 48/46 idol group, though she working for it by exploring it intensely. Dev's oshimen in 48/46 idol group are Shiraishi Mai, Eto Misa, Ikuta Erika, Kojima Haruna, Kashiwagi Yuki, and Watanabe Mayu. Like Sandi's case, except for Ikuta, all her oshimen are over 20 years old (while Kojima Haruna turns 28). Dev reveals she is uncomfortable to idolize someone much younger than herself. "Feel old is odd", so the reason she expressed.

Although new, Dev already has a variety of merchandise that she collected. She collects notebooks, jackets, t-shirts, and CDs. There are interesting things from the criteria of items that Dev wanted: they should be usable. "Not my intention to boast or else, but if the jacket or collectible items that can be used as a part of ourselves, yes ... So we feel to have a closer relationship with oshimen". For Dev, collecting merchandise is somewhat related to her contributing factors to the group and as a means of presenting a sense of engagement in the fandom world. Dev avoids buying magazines that contain gravure photos because they are uncomfortable. "It's strange, like see your own sister watched by many people. And as a woman, I do not want to sexualize them." Just like Sandi, Dev also admitted that she was impulsive when buying merchandise "If you really love your oshi, you'll willing to buy anything"

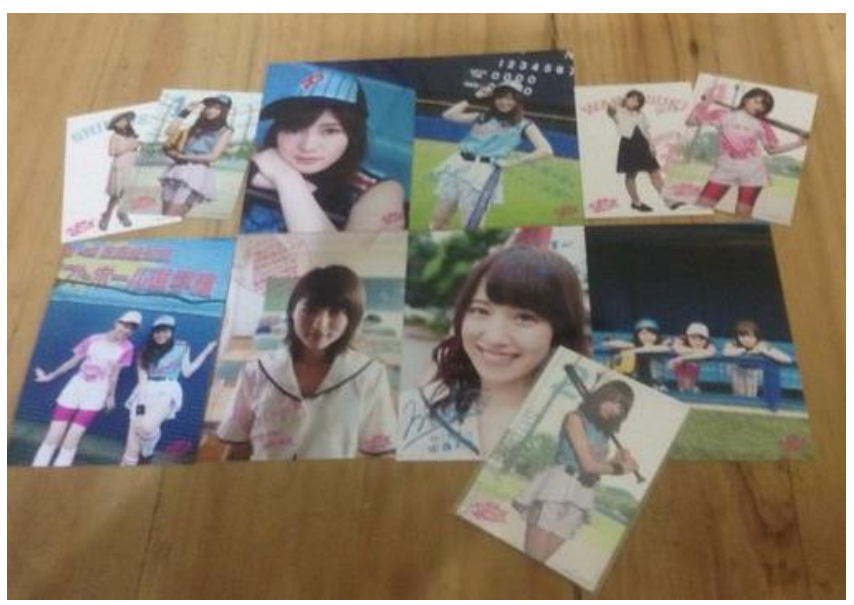

Fig. 9 Dev's Collection

Different motivations expressed by Annisa H. The 19-year-old student clearly reveals if the merchandise is a memorandum of her oshimen. Unsurprisingly, considering she idolized the $2^{\text {nd }}$ generation AKB48, in which its last member, Umeda Ayaka, officially graduated from the group on 1 April 2016. "I collect Ume's stuff as a reminder. Oh, there is a member, Umeda Ayaka, I am big fans of her ". For Annisa, Umeda is her inspiration. "She is not a member who is favored by management, but she can go all the way to senbatsu in 2011-2012. For me, Ume is a manifestation of something like you can do it if you work hard, suffer, all the same". After Ume's graduation, Annisa chose Kamieda Emika as her oshimen. "I like the unpopular after all, hehehe .... more likely she is the interesting and unique character". Annisa visited Japan in March and bought many merchandises at the official store. "I was mistaken (laugh). They are going to offer something beyond our expectation and we ended up buying it." 


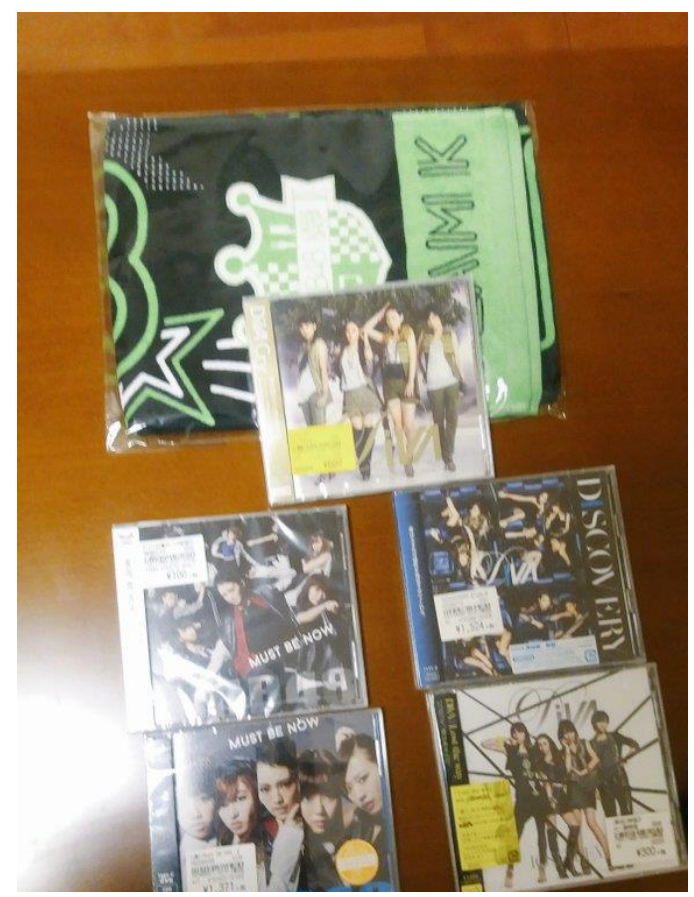

Fig. 10 Annisa's collection

\section{Conclusions}

Of the three respondents, we can see some similarities. They acknowledge that what they do is not a rational activity. For them, collecting merchandise is something that reinforces their existence as fans. Cogito ergo sum, I think therefore I am, says Rene Descartes. The same principle expressed by the fans, I collect therefore I exist as a fan. Through their collections, they feel like fans who are 'intact', the truest fans.

In case of existence, the question of identity is unavoidable. Those who collect merchandise want to establish their identity as fans; they want to be known as fans. Most of the merchandise produced does not have a practical use, though they pursue other values that exist from it. There is a pride aspect in it; there are aspects of pursuing authenticity. The three respondents acknowledged that they only bought the original merchandise produced by the group's management because it was one form of their support for oshi. Such motivation is in line with the exposure of Pearce who proposed 17 factors that make a person collect a good (McIntosh and Schemichel, 2004, p. 87), Some of them are found in the motivation expressed (both implied and written) by the respondents, namely: leisure, extending self, a sense of community, and prestige. Even there are so many motivations but all that leads to two things: self-fulfilling and selfenhancement

The identity factor as a fan also influences the consumption pattern made by the respondents. Through the concept of oshimen, they directly practice a specialized consumption pattern. Referring to the statement of the respondents, mostly of their merchandise collections are merchandises that displays their oshimen. Even if they do not buy oshi-displayed merchandise, they will buy the merchandise that closely related with their oshimen. Sandi's case becomes one brief example, he bought Team K's lightstick because Mogi is a member of the team. Then a conclusion considered if the identity is something to achieve as well as a basic motivation of consumption patterns made by the respondent.

Lattermost, there is no satisfaction expressed by the respondents. They always wanted to collect the latest merchandise releases from their oshimen. Identity, according to Giddens, is something that must preserve throughout life. Identity is a lifetime project that continues, and therefore he/she should continue to form and maintained throughout life. Fans did the same to keep his/her identity. They will continue to collect merchandise to keep their identity as fans. While still, the fandom exists, they will not stop collecting merchandise. 
Acknowledgments My sincere thanks go to: $\bullet$ Sandi - for being a fellow wota and a good senior. Thank you for our endless discussion that gives me interesting perspectives for this project. • Dev - for being a passionate fan, despite being new to this fandom. Thanks for your womanly view that gives me something to think about. Something so important to me as a fan and as a researcher. $\bullet$ Annisa - my dear little sister. For always answering my midnight chatting. Do your best at your study.

\section{References}

Belk, R.W. (1988). Possessions and the extended self. The Journal of consumer research, 15(2), 139-168.

Galbraith, P.W., and Karlin, J.G. eds. (2012). Idols and Celebrity in Japanese Media Culture. 21. Hampshire: Palgrave Macmillan.

Giddens, A. (1991). Modernity and Self-Identity: Self and Society in the Late Modern Age. 14. London: Polity Press.

McIntosh, W.D. and Schmeichel, B. (2004). Collectors and collecting: A social psychological perspective. Leisure Sciences, 26(1), 85-97.

Stevens, C.S. (2010). You are what you buy: Postmodern consumption and fandom of Japanese popular culture. Japanese Studies, 30(2), 199-214. 